\title{
Gonorrhoea and foreign immigrants at Rotterdam University Hospital*
}

\author{
H. VERKLEIJ \\ From the Department of Dermatology, University Hospital, Rotterdam, The Netherlands
}

\section{Summary}

It is estimated, contrary to public opinion and a quick glance at the waiting room of the sexually transmitted diseases (STD) clinic in Rotterdam, that the incidence of gonorrhoea among foreign immigrants is only a little greater than among the Dutch population. The analysis corroborates the common sense idea that the higher incidence of gonorrhoea among foreign immigrants stems largely from their difficulty in finding sexual partners. To solve this problem is a matter of national policy. It is within the scope of the STD clinics and related organizations to start small-scale experiments to improve the difficult medical situation of the foreign immigrants by lowering the linguistic and cultural barriers between the medical staff and their foreign patients. Research on the sexual habits of the patients is of limited value, and a redirection of our efforts seems necessary to tackle this problem.

\section{Introduction}

Foreign immigrant workers are a recent phenomenon in the Netherlands, their number having risen from 8,000 in 1960 to 140,000 in 1973 (Figure), and medical interest in them is increasing. It appears from looking into the waiting room of the sexually transmitted diseases (STD) clinic at Rotterdam that Dutchmen have comparatively low infection rates and that foreign immigrants are prone to catch STD. This article tries, by analysing existing data, to make a more sophisticated examination of this problem and to find explanations for the higher incidence of STD among foreign immigrants. $\dagger$

\footnotetext{
Received for publication July 23, 1975

* Revised version of a paper presented at the 28th General Assembly of the IUVDT, Malta, April, 1975

Address for reprints: Polikliniek Dermatologie, Akademisch Ziekenhuis, Rotterdam, The Netherlands

†Data kindly supplied by Dr. Stolz, head of the STD Clinic, Rotterdam University Hospital
}

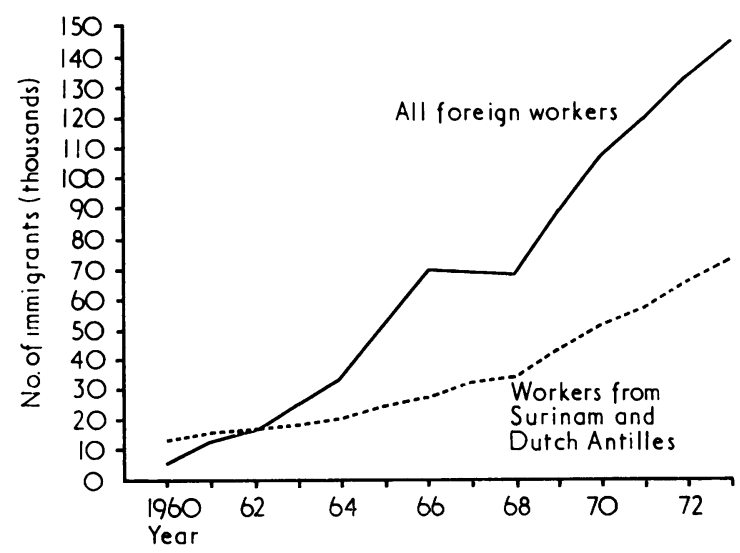

FIGURE Number of foreign immigrants (thousands; women and children included) in the Netherlands, 19601973 (from van Houte and Melgert (1972), p.192)

\section{Methods}

(1) Case histories

During the period from October, 1971, to December, 1973, a sexual case history was compiled for each patient with gonorrhoea who attended the STD clinic of Rotterdam University Hospital.

The questions relevant to this study were :

(a) Age, sex, marital status, and nationality of the patient

(b) Number of contacts

(c) Nationality of contact, relation with contact, first meeting place, and contraceptive method used

(d) 3 months after the interrogation the contact tracing was considered to be closed and the results were then linked with the case history of the patient

(2) The interviewer

During the first 9 months, the case history was compiled by one doctor, who had set up this study, without the aid of official interpreters. Sometimes a fellow-patient with better command of the Dutch language was asked to assist, sometimes English or another language could better serve as the common language than Dutch, and occasionally the case history had to be compiled by means of gestures. In the latter part of this study the case history was compiled largely by one female social worker. 


\section{(3) Nationality}

The foreign immigrants come especially from countries around the Mediterranean, namely : Portugal, Spain, Italy, Yugoslavia, Greece, Turkey, and Morocco. The Surinamese and Netherlands Antillians are dealt with separately. Although they speak Dutch and have Dutch nationality, their situation is in many respects similar to that of the foreign workers.

(i) Many of them have come to the Netherlands recently and have problems adapting to a new climate and culture.

(ii) They are economically underprivileged, they tend to work in unskilled jobs, and they live in poor housing concentrated in the oldest parts of the city.

(iii) There is little integration with the Dutch population

(iv) There are more male than female Surinamese immigrants.

(v) They are set apart by their skin colour

(4) Statistical analysis

All patients attending during the research period are included in the study, so that no statistical tests of significance are needed. From a statistical point of view the results are not to be extrapolated to other STD clinics in the Netherlands or elsewhere, because the study was done in one clinic, and one cannot generalize from one sample.

\section{Results}

(1) Incidence of gonorrhoea

On the whole gonorrhoea among the foreign immigrants seems to occur mainly in males. The numbers from the different countries are shown in Table I.

TABLE I Cases of gonorrhoea diagnosed at the Rotterdam University Hospital, by sex and nationality, October, 1971, to December, 1973*

\begin{tabular}{|c|c|c|}
\hline \multirow{2}{*}{ Country of origin } & \multicolumn{2}{|l|}{ Sex } \\
\hline & Male & Female \\
\hline Spain & 26 & - \\
\hline Turkey & 55 & 1 \\
\hline Yugoslavia & 44 & 5 \\
\hline Portugal + Cape Verde Islands & 50 & 2 \\
\hline Morocco & 57 & 1 \\
\hline Italy & 43 & - \\
\hline Greece & 13 & 1 \\
\hline Total foreigners & 288 & 10 \\
\hline Surinam + Netherlands Antilles & 164 & 50 \\
\hline Netherlands & 603 & 528 \\
\hline
\end{tabular}

$\star^{\star}$ Repeated infections excluded

Among the foreign patients only ten out of 300 are female. The number of Surinamese female patients is higher, because there are more of them in the Netherlands compared with other immigrant groups. The incidence of STD in females has not been calculated. In males the figures have been restricted to the 20 to 34 -year age group; this is because the municipal statistical bureau uses only the 16 to 19 -year, 20 to 34 -year and 35 to 64 -year age groups. Because of the known different risks in married and single persons and the unequal balance of married and single persons within the different national groups, it is necessary to divide the figures into these two categories. This has been done for patients and the general population in Table II. The main conclusion from this Table is that some of the numbers in the different categories are so low that reliable incidence rates can be obtained only by combining the figures for the Mediterranean nationalities.

TABLE II Cases of gonorrhoea in men aged 20 to 34 years diagnosed at the Rotterdam University Hospital, October, 1971, to December, 1973, by nationality and marital status, compared with total number of men of same nationality in Rotterdam

\begin{tabular}{|c|c|c|c|c|}
\hline \multirow{2}{*}{ Country of origin } & \multicolumn{2}{|c|}{ No. of patients ${ }^{\mathrm{a}}$} & \multicolumn{2}{|c|}{ Total men ${ }^{\mathrm{b}}$} \\
\hline & Single & Married & Single & Married \\
\hline Spain & 16 & 3 & 365 & 849 \\
\hline Turkey & 18 & 25 & 178 & 1,364 \\
\hline Yugoslavia & 25 & 13 & 915 & 958 \\
\hline \multicolumn{5}{|l|}{ Portugal + Cape Verde } \\
\hline Islands & 15 & 16 & 162 & 372 \\
\hline Morocco & 20 & 27 & 227 & 643 \\
\hline Italy & 32 & 1 & 157 & 157 \\
\hline Greece & 2 & 6 & 43 & 77 \\
\hline Total foreigners & 128 & 91 & 2,048 & 4,421 \\
\hline $\begin{array}{l}\text { Surinam + Netherlands } \\
\text { Antilles }\end{array}$ & 100 & 28 & 1,389 & 847 \\
\hline Netherlands & 299 & 141 & 30,383 & 37,600 \\
\hline
\end{tabular}

Table III, which shows the annual incidence of gonorrhoea in men aged 20 to 34 years, leads to the following conclusions:

(i) Incidence differs between nationalities

(ii) Incidence is higher among the unmarried than among the married

(iii) Incidence among foreign workers and Surinamese is six to seven times higher than among the Dutch

Concerning the last result, two remarks must be made. The figures for Dutch nationals does not include the so-called illegal foreign immigrants, although these immigrants sometimes attend the STD clinic. Were they included, the incidence among the foreign workers would be roughly 20 per cent. lower. Secondly, the clinic may especially attract foreign patients, and if this were taken into account, it too would lower the apparent incidence in foreigners. Nevertheless, the incidence among foreign workers would still be at least three times 
higher than amongst the Dutch; this difference is about the same as that between married and single persons (Table III).

TABLE III Annual incidence of gonorrhoea per 1,000 males aged 20 to 34 years, by nationality and marital status, based on the 1972-1973 figures of the Rotterdam University Hospital ${ }^{\star} \dagger$

\begin{tabular}{|c|c|c|}
\hline \multirow{2}{*}{ Country of origin } & \multicolumn{2}{|c|}{ Marital status } \\
\hline & Single & Married \\
\hline $\begin{array}{l}\text { Spain } \\
\text { Turkey } \\
\text { Yugoslavia } \\
\text { Portugal + Cape Verde Islands } \\
\text { Morocco } \\
\text { Italy } \\
\text { Greece }\end{array}$ & $\begin{array}{l}20 \\
45 \\
12 \\
41 \\
39 \\
91 \\
21\end{array}$ & $\begin{array}{r}2 \\
8 \\
6 \\
19 \\
19 \\
3 \\
35\end{array}$ \\
\hline Total foreigners & 28 & 9 \\
\hline Surinam + Netherlands Antilles & 32 & 15 \\
\hline Netherlands & $4 \cdot 4$ & $1 \cdot 7$ \\
\hline
\end{tabular}

* Repeated infections excluded

†Rotterdam University Hospital covers an estimated 50 per cent. of all cases of gonorrhoea in Rotterdam

\section{(2) Case histories}

The higher incidence among foreign workers may be largely explained by their difficult sexual situation, in that they have little chance of establishing a steady sexual relationship with a Dutch female. This situation is reflected in the answers they give when their case history is taken. From Table IV the following conclusions may be drawn:

(i) Foreign workers have fewer partners than the Dutch and the Surinamese.

(ii) They are highly dependent on Dutch women; nearly three-quarters of their partners being Dutch. The percentage for the Surinamese is somewhat lower, as there are more Surinamese women in the Netherlands.

(iii) The foreign workers' contacts with amateurs, pick-ups, and prostitutes are nearly always casual.

TABLE IV Characteristics of male patients and their contacts by nationality

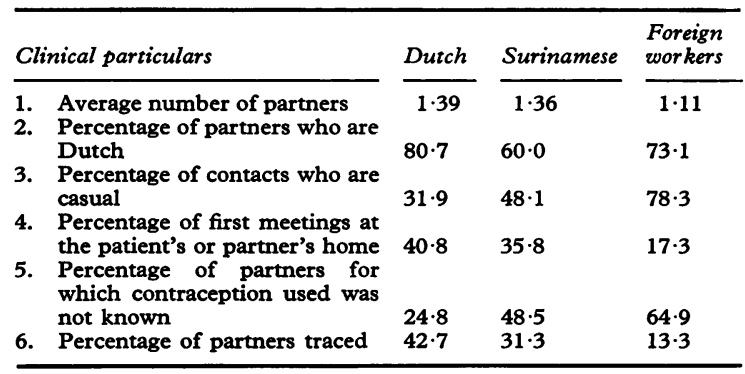

(iv) The Dutch patients make many of their contacts at parties or during visits of friends and acquaintances, but the foreign workers are dependent on casual contacts at streetcorners, in bars or dance-halls, and in brothels.

(v) These casual relationships are reflected in the the fact that the foreign workers rarely know what contraception their partners are using.

(vi) It is no wonder that these casual relationships, plus language difficulties, lead to a low frequency of contact tracing.

In most of the particulars listed in Table IV the Surinamese take an intermediate position between the foreign workers and the Dutch. This may be attributed to their better integration within Dutch society, or to the better balance between males and females within the Surinamese group.

\section{Discussion}

It is possible that the differences between nationalities may be attributable to differences in the taking of the sexual case histories. For instance, the foreign immigrants name fewer contacts, but one may argue that they conceal subsequent contacts after being interrogated about the first one, finding the procedure tiresome because of language difficulties. No special provision was made for interviewing the foreign patients, apart from the genuine interest of the doctor who interviewed them, so we have to accept this uncertainty.

As to the main conclusion of this study, that the gonorrhoea problem among the foreign immigrants is largely attributable to their sexual situation, this analysis gives no final proof, but only additional and non-contradictory evidence. It could be argued that the foreign immigrants who do not catch gonorrhoea establish stable relationships with Dutch females, but information from other sources contradicts this. The Dutch attitude to foreigners in sexual matters is reflected in the fact that, in the one traditional red-light quarter of the town, some brothels cater especially for Turkish and Moroccan customers, because most prostitutes do not want them as customers and despise those who do. Lamb (1966), Willcox (1966), and Hossain (1971) also concluded that immigrants elsewhere had difficulty in finding sexual partners.

The results of this study support the view that the high incidence of gonorrhoea among immigrants is largely due to a difficulty in obtaining sexual partners, but other reasons must exist because the Surinamese, although better integrated into Dutch society and having more Surinamese women available, also have about the same incidence as the whole group of foreign immigrants. 


\section{Policy suggestions}

To counter the lack of sexual partners for foreign workers, it would be logical to attract as many females as males from the same country, to make it easier for the wives of foreign workers to come to the Netherlands, to promote the integration of the foreign immigrants into the Dutch society, or not to attract foreign workers at all.

These are matters of national policy. The venereologist can only publish his findings, so that the authorities may take the necessary measures. Another aspect of the problem is that foreign immigrants are in a difficult medical situation, and in this the STD clinics and related organizations can assist. The first suggestion is to give foreign immigrants more information about STD. This can be done by translating information brochures after they have been adapted to the mentality of the immigrants; by devising special radio programmes for them; by writing articles in their own periodicals ; and by showing slides in the waiting rooms in the STD clinics.

There is also the language barrier between doctor and nurses on the one hand and the foreign workers on the other. Three things seem to be important in this connection:

(i) It is important to realize that helping a foreign patient takes longer than helping a Dutch patient, and that this extra time should not be considered as wasted. This fact should be taken into account when defining the patient load per doctor and per nurse.

(ii) Clear criteria should be laid down about the use of an interpreter. At the moment, because there is no organization, interpreters are only used in cases of exceptional difficulty. (iii) When an interpreter is not available or not considered necessary, visual aids should be used for compiling the case history and giving instructions to the patient.

Our present medical facilities, which are designed to suit Dutch patients, must appear strange to foreigners and cause them anxiety. For instance people of one nationality fear the taking of blood, and those of another are afraid of specimens being taken from the urethra, while those of a third do not understand that they have to return after treatment for follow-up visits. Time must be devoted to these problems and an effort made to suit the clinics to the needs and customs of foreign workers. The best way to do this is by starting small-scale experiments.

\section{Research and policy}

In essence all these suggestions have already been made by Willcox (1966) and Hossain (1970), but since these suggestions were made, nothing has been done, although everyone who has consulted a doctor in another country can understand the feelings a foreign immigrant must have in the same situation. This means that it is much easier to do research on the sexual case histories of patients than to put these recommendations into practice. This very article gives further proof of this fact. Our efforts should be redirected to these substantial problems.

\section{References}

Hossain, A. S. M. T. (1970) Hlth Educ. F., 29, 135 (1971) Soc. Sci. and Med., 5, 227

Houte, H. vaN, and MeLGeRT, W. (1972) 'Foreigners in our Community', p. 192. Keesing, Amsterdam

LAMB, A. M. (1966) Brit. F. veiler. Dis., 42, 276

WILlCox, R. R. (1966) Ibid., 42, 225 